\title{
Comparative study of eutectic Al-Si alloys manufactured by WAAM and casting
}

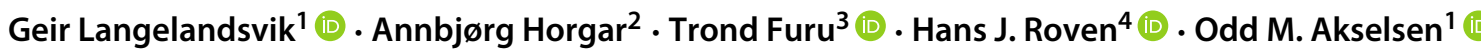

Received: 15 February 2020 / Accepted: 6 July 2020 / Published online: 17 August 2020

(C) The Author(s) 2020

\begin{abstract}
Wire and arc additive manufacturing (WAAM) of metallic materials is expected to become part of the new industrial revolution. The possibilities for complex designs and superior mechanical properties can in many cases replace traditional manufacturing processes such as casting. In order to benchmark the properties of aluminium WAAM components, a comparative study was performed with two different casting techniques: permanent casting with steel mould and sand mould casting. Aluminium-silicon alloys with near eutectic composition were used for the comparison. Porosity levels, secondary dendrite arm spacing, grain size distribution, tensile strength and microhardness were considered for the comparison. The WAAM material exhibited superior mechanical properties originating from a finer dendritic and eutectic microstructure compared with the castings. A slight anisotropy in tensile ductility was observed in the WAAM material, probably due to a coarse microstructural zone between individual beads. All investigated materials had low levels of porosity, $<1 \%$ by area fraction. The comparative study has shown that WAAM of aluminium-silicon alloys is well suited for high-integrity applications.
\end{abstract}

Keywords Wire + arc additive manufacturing $\cdot$ Casting $\cdot$ Aluminium $\cdot$ AA4047 $\cdot$ Microstructure $\cdot$ Mechanical properties

\section{Introduction}

The potential to create complex metallic components with superior functional and mechanical properties has encouraged extensive research on additive manufacuring (AM) $[1,2]$. Economical as well as environmental benefits such as reduced production lead times and material usage are driving forces for the adaption of AM into the industry. AM has already been utilised in manufacturing of boat propellers, aircraft engine brackets, fuel nozzles and water distribution manifolds, among others [3-5].

Geir Langelandsvik

geir.langelandsvik@sintef.no

1 SINTEF Industry, 7491 Trondheim, Norway

2 Department of Mechanical and Industrial Engineering, NTNU Norwegian University of Science and Technology, 7491 Trondheim, Norway

3 Norsk Hydro, Corporate R\&D Headquarter, 0283 Oslo, Norway

4 Department of Materials Science and Engineering, NTNU Norwegian University of Science and Technology, 7491 Trondheim, Norway
Wire and arc additive manufacturing (WAAM) is one of the most promising AM techniques. Being a successor of layer-wise welding patented by Baker [6], WAAM employs metallic wire and electric arc welding for strategic deposition of material on a substrate. The deposited material is subjected to repeated solidification and remelting, giving good adhesion between layers and a complex thermal history. WAAM shows very high deposition rates compared with other AM processes, i.e., up to $10 \mathrm{~kg} / \mathrm{h}$ for ferrous alloys and $1 \mathrm{~kg} / \mathrm{h}$ for aluminium [7].

The main volume of literature on metal additive manufacturing is based upon titanium and its alloys [8]. Research has also been conducted on ferrous materials, nickel superalloys, magnesium alloys, intermetallics and high-entropy alloys [9-15]. WAAM of aluminium and its alloys has been challenging for several reasons. Extensive pore formation is often experienced due to a high affinity to oxygen and a large difference in liquid- and solidstate hydrogen solubility $[16,17]$. Poor inert gas shielding from air, hydrocarbon contaminants on the filler wire and moisture are common sources for porosity [18]. A clear relation between increasing porosity level and shorter fatigue life has been shown by Sonsino and Ziese [19], as pores act as stress concentration sites for nucleating cracks. 
Several aluminium alloys are susceptible to hot tearing and solidification cracking during WAAM or layer-wise welding, due to an extensive shrinkage upon solidification and long solidification intervals. Hence, alloys suitable for WAAM are restricted to a limited number of alloy systems. Selected wrought alloys from the 2xxx (Al$\mathrm{Cu}), 4 \mathrm{xxx}(\mathrm{Al}-\mathrm{Si})$, and $5 \mathrm{xxx}(\mathrm{Al}-\mathrm{Mg})$ systems have been shown feasible for WAAM [20-24]. Haselhuhn et al. [25] compared the mechanical properties of several aluminium alloys manufactured by WAAM and found the Al-Si alloy AA4047 with near eutectic composition highly suitable for WAAM. A similar result was reported by Heard et al. [26].

Few literature sources encompass cooling rates and resulting properties of WAAM components. However, established knowledge from casting technology can provide valuable insight on these terms. Since casting represents a competition to WAAM technology, a comparative study between WAAM and casting could be rewarding. Thus, this study will examine the microstructural and mechanical properties of eutectic Al-Si alloys subjected to WAAM and two different casting methods. The latter includes steel mould and sand mould casting.

\section{Materials and methods}

The aim of this study was to compare the properties of eutectic Al-Si alloys after different processing routes. The performed activities are summarised in Fig. 1 and described in detail in the following paragraphs.

\subsection{Materials}

The chosen material for WAAM was the Al-Si alloy AA4047 in the form of a wire with diameter $1.2 \mathrm{~mm}$. The alloy chemical composition is given in Table 1. AA4047 provides excellent weldability with a low degree of porosity and is not considered susceptible for hot cracking. WAAM

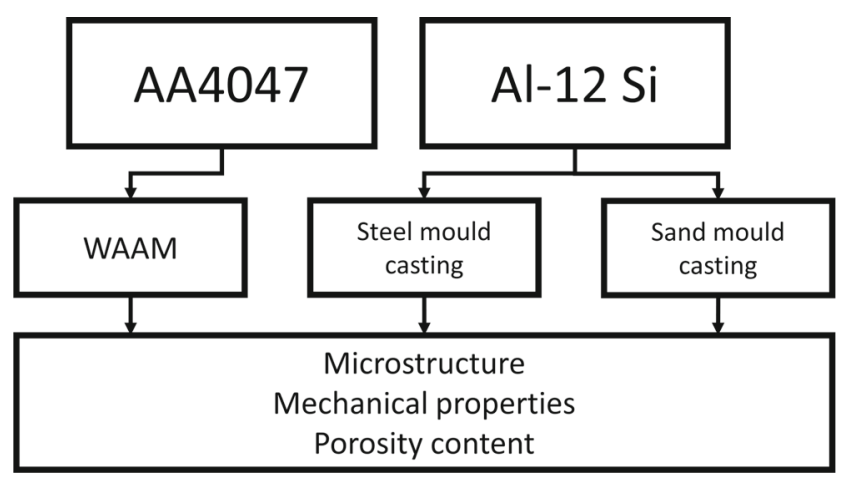

Fig. 1 Flowchart for comparative study of eutectic Al-Si alloys manufactured by WAAM and casting was performed on a fixed substrate, consisting of an AA6082 (Al-Mg-Si) rolled plate in the T6 condition with dimensions $15 \mathrm{~mm}$ thickness, $260 \mathrm{~mm}$ width and $334 \mathrm{~mm}$ length.

A direct chill (DC) cast ingot with near-eutectic AlSi composition was chosen for casting. It was produced by Hydro Aluminium, R\&D Centre, Sunndalsøra, Norway. The alloy composition is given in Table 1. It should be mentioned that $150 \mathrm{ppm}$ of $\mathrm{Sr}$ was added to the melt in order to refine the flaky silicon eutectic formed during solidification. The modification mechanism has been described by Shamsuzzoha and Hogan [27].

\subsection{WAAM}

The WAAM assembly consisted of a six degrees of freedom robot arm (ABB IRB2400), the AA6082 plate clamped to a stationary substrate table, gas metal arc welding (GMAW) power source (Fronius TPS 400i) and the AA4047 wire. The target WAAM design was a 70-mm-high, 100-mmwide and 180-mm-long massive block. A CAD model of the WAAM deposit is shown in Fig. 2a, where also tensile bar specimen orientations and the reference coordinate system are indicated. $X$ and $Y$ directions are defined as parallel and perpendicular to the deposition direction, respectively. The $Z$ direction is defined as the through thickness orientation. The robotic movement was implemented as G-code through the RobotStudio ${ }^{\circledR}$ software. The block design enabled tensile testing in three perpendicular directions. The as-built WAAM block is shown in Fig. $2 b$.

The WAAM block constituted of 39 layers with 17 weld passes in each layer. In total, 658 passes with length of 180 $\mathrm{mm}$ was deposited. The passes in each layer was deposited in a 'zigzag' pattern, i.e. from A to B then B to A. A dwell cooling time of $60 \mathrm{~s}$ was performed after each pass. The dwell time was increased to $120 \mathrm{~s}$ upon completion of one layer, i.e. after every 17 th pass. The deposition direction was parallel to the $X$ direction (see Fig. 2a). Total build time was $18 \mathrm{~h}$.

Two distinct sets of GMAW parameters were chosen. A high-energy arc mode for the three initial layers was used in order to avoid an undulating surface and to ensure good bonding to the substrate plate. The second parameter set was a low-energy arc steady state mode and was kept constant throughout the remaining building process. All utilised parameters are presented in Table 2 as an average of the median value from each weld pass. The arc energy $(A E)$ was calculated through Eq. $1 . U$ and $I$ are torch voltage and current, respectively. $T S$ is the robot travel speed. Contact tip to work distance (CTWD) was held constant at $12 \mathrm{~mm}$.

$A E=\frac{U I}{T S}$ 
Table 1 Chemical composition of investigated materials in wt.\% [28]

\begin{tabular}{llllllllll}
\hline Product & $\mathrm{Si}$ & $\mathrm{Fe}$ & $\mathrm{Sr}$ & $\mathrm{Cu}$ & $\mathrm{Mn}$ & $\mathrm{Mg}$ & $\mathrm{Zn}$ & $\mathrm{Ti}$ & $\mathrm{Al}$ \\
\hline WAAM & 11.6 & 0.13 & 0.03 & 0.004 & 0.001 & 0.002 & 0.002 & 0.02 \\
Cast & 12.7 & 0.13 & 0.01 & 0.001 & 0.004 & 0.008 & 0.002 & 0.01 & Balance \\
\hline
\end{tabular}

\subsection{Casting}

The Al-12Si DC cast ingot was melted in an induction furnace at $700-730{ }^{\circ} \mathrm{C}$ before $150 \mathrm{ppm} \mathrm{Sr}$ was added to the melt. The melt was then casted by two different techniques: permanent steel mould casting and sand mould casting. Steel mould casting was performed with a preheated mould held at $200{ }^{\circ} \mathrm{C}$. The temperature was monitored by a $\mathrm{K}$ type thermocouple with an adequate sensibility for the current temperature range. Other thermocouples with higher accuracy could also have been selected. The steel mould had a blunt end to resemble a weld bead geometry (see Fig. 3). The mould bottom experiences a directional solidification regime which resembles WAAM and was the area of microstructural and microhardness investigations. A riser on top of the steel mould ensured sufficient backfilling giving a dense casting. The liquid metal was poured by a tilt-casting principle in order to avoid turbulence. Due to the relatively high thermal conductivity of steel and the narrow design, a high cooling rate was achieved.

Sand moulds were made by using a permanent mould casting with riser as impression. Liquid Al-12Si melt was poured into the sand mould by the tilt principle and held for $30 \mathrm{~min}$ before dissembling the sand mould. The mould held a constant temperature of $20^{\circ} \mathrm{C}$ throughout the casting. Sand moulds have lower thermal conductivity compared with moulds made of steel, and resulted in a low cooling rate of the casted material. By this approach, it was possible to examine three different regimes of cooling rates and resulting properties; WAAM, steel mould casting and sand mould casting.

\subsection{Characterisation}

The produced materials were subjected to metallographic inspection by light optical microscopy and scanning electron microscopy (SEM). Samples were prepared for microstructural examination through standard metallographic procedures including mechanical grinding with water-lubricated silicon carbide discs and polishing on cloths with water-based diamond suspensions. Vibratory polishing using colloidal silicon dispersion with diameter equal $0.02 \mu \mathrm{m}$ was used at the final stage to obtain a deformation-free and mirror-like finish. The area fraction of porosity in the inspected materials was examined by optical microscopy. Areas $(10 \mathrm{~mm} \times 10 \mathrm{~mm})$ consisting of $\sim 150$ images with $100 \times$ magnification were stitched together by the Leica Application Suite software to obtain a credible porosity map. The measurement locations and corresponding macrographs of the WAAM wall are shown in Fig. 4. The image mosaic was further processed by the open-source software ImageJ in order to quantify the area percentage porosity. Dendritic microstructures were revealed by etching in Keller's reagent for $15 \mathrm{~s}$. The secondary dendrite arm spacing $\lambda_{2}$ was estimated by counting $N$ arms over a length $L$ through the relation $\lambda_{2}=$ $L /(N-1)$ [29]. Crystallographic data was retrieved by SEM electron backscatter diffraction (EBSD) followed by postprocessing applying the TSL OIM Analysis 7 software. An area of $500 \mu \mathrm{m} \times 500 \mu \mathrm{m}$ was examined for each material condition by EBSD. The index step size ranged from 1 to $2 \mu \mathrm{m}$, dependent on the average grain size of each material.
Fig. 2 AA4047 block manufactured by WAAM. $X$ and $Y$ directions are defined as parallel and in-plane perpendicular to the deposition direction, respectively. $Z$ direction is along the through thickness of the component



(a) CAD model showing tensile specimen ori-

entation and position

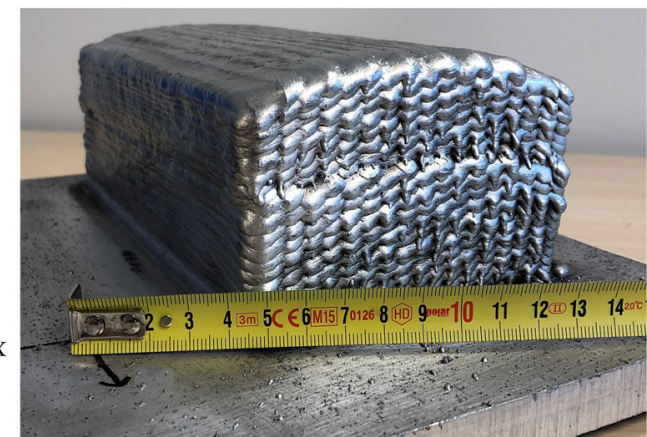

(b) Deposited WAAM block 
Table 2 GMAW input parameters for WAAM

\begin{tabular}{lll}
\hline Parameter & Layers $1-3$ & Layers 4-38 \\
\hline Current $I(\mathrm{~A})$ & 162 & 137 \\
Voltage $U(\mathrm{~V})$ & 23.2 & 21.9 \\
Travel speed $T S(\mathrm{~m} / \mathrm{min})$ & 0.54 & 0.54 \\
Wire feed speed $W F S(\mathrm{~m} / \mathrm{min})$ & 7.6 & 6.3 \\
Arc energy $A E(\mathrm{~kJ} / \mathrm{m})$ & 418 & 333 \\
Contact tip to work distance (CTWD) (mm) & 12 & 12 \\
\hline
\end{tabular}

Both the WAAM and the steel mould casting materials were subjected to tensile testing in a servohydraulic MTS 810 tensile machine with stroke rate $\sim 2 \mathrm{~mm} / \mathrm{min}$ until fracture occurred. Three perpendicular directions were tested from the WAAM block, i.e. along the $X, Y$ and $Z$ directions (see Fig. 2a). Tensile testing of castings was restricted to one direction due to mould design limitations. The gauge area was in the central part of the casting (Fig. 3). Tensile results were subjected to two-tailed Student's $t$ test for two independent means with significance level 0.05 . Vickers microhardness testing was performed applying 0.1 kilogram force $\left(\mathrm{HV}_{0.1}\right)$ using a Leica VMHT MOT microhardness indenter. Each indentation had a centre-tocentre distance of $350-400 \mu \mathrm{m}$, in accordance with ISO 6507-1:2018. The indentations were patterned as a matrix in order to highlight eventual hardness fluctuations. For the WAAM block, the face perpendicular to the deposition direction (i.e. YZ-plane) was investigated by means of microhardness.

\section{Results and discussion}

\subsection{Microstructure}

Solidified castings and welds of aluminium alloys are seldom fully dense. Entrapped gas and shrinkage during solidification can leave voids and cracks in the solidified structure, reverting the mechanical integrity of components. Thus, porosity is generally unwanted. The area percentage porosity found in the examined materials is presented in Fig. 5. The WAAM material shows low levels of porosity in bulk, less than $0.2 \%$ (area percentage). It can be added that cavities were evenly spread out in the structure. The pore geometry was solely governed by entrapped gas which exhibited a spherical shape.

The presented WAAM material exhibited a very low porosity content compared with values reported in the literature. Wang et al. [22] manufactured thin walls by WAAM with the AA4043 Al-5Si alloy and measured a density ranging between 99.2 and $99.8 \%$, dependent on welding parameters. Thus, the density was similar or slightly lower compared with the results presented in this study. For the same alloy AA4043, Ortega et al. [30] measured an area percentage porosity ranging from 0.90 to $1.88 \% \pm 0.23 \%$. An AA4047 WAAM thin wall by Haselhuhn et al. [25] possessed an average area porosity of $0.8 \% \pm 0.1 \%$, i.e. more porous than the presented AA4047 WAAM block.

For other alloy systems commonly subjected to WAAM, porosity levels are similar to the aforementioned. Ryan et al. [31] measured the porosity of AA2319 thin walls as a
Fig. 3 Permanent steel mould with dimensions in $\mathrm{mm}$ (left). Illustration of half the steel mould (right)



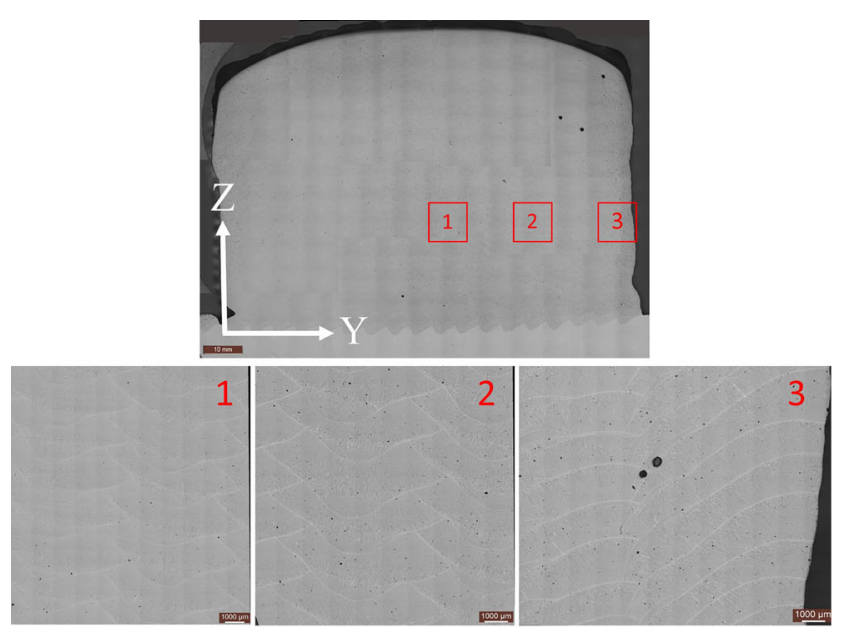

(a) WAAM block in $Y Z$ plane

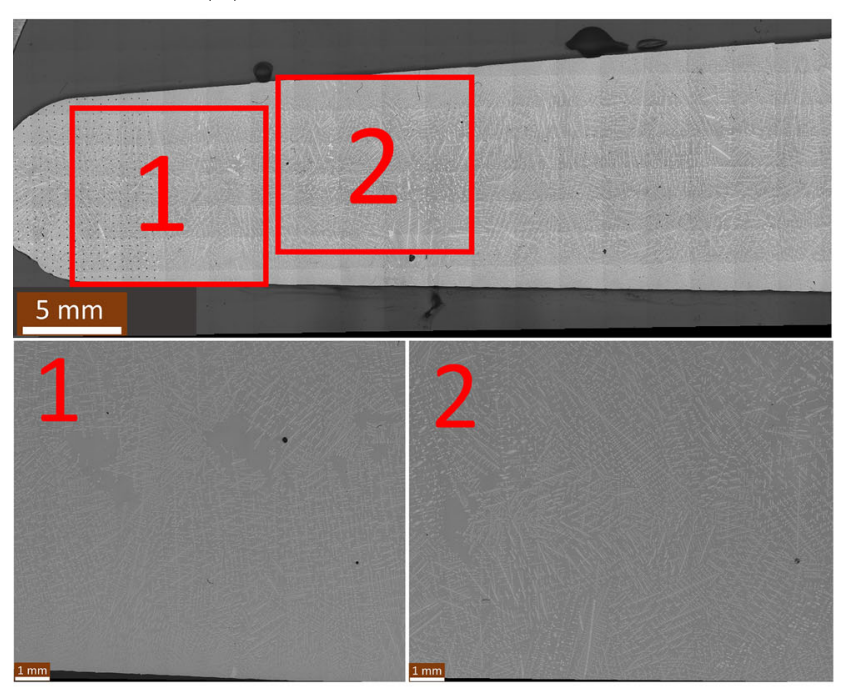

(b) Permanent steel mould casting
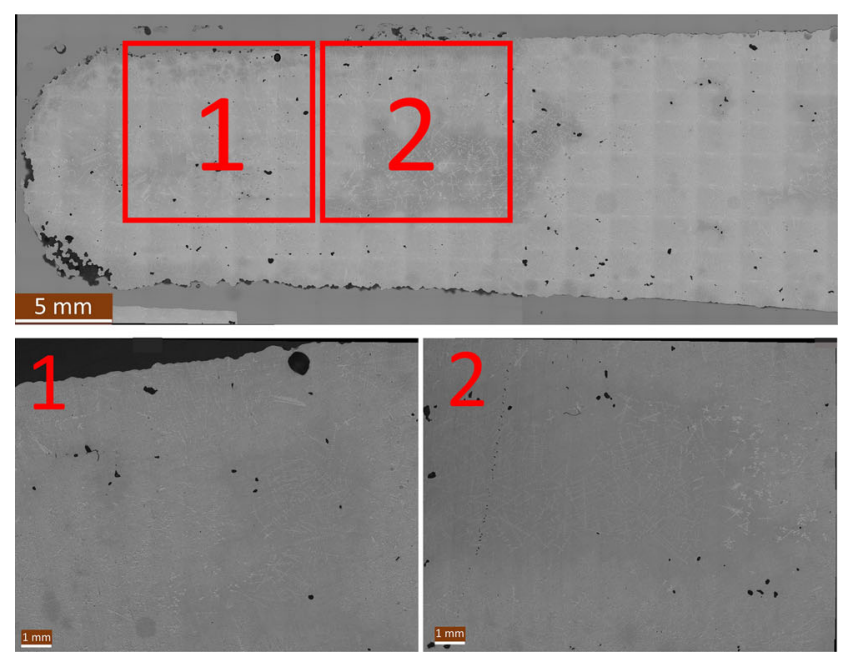

(c) Sand mould casting

Fig. 4 Examination positions for porosity content, microstructure and microhardness in the investigated materials

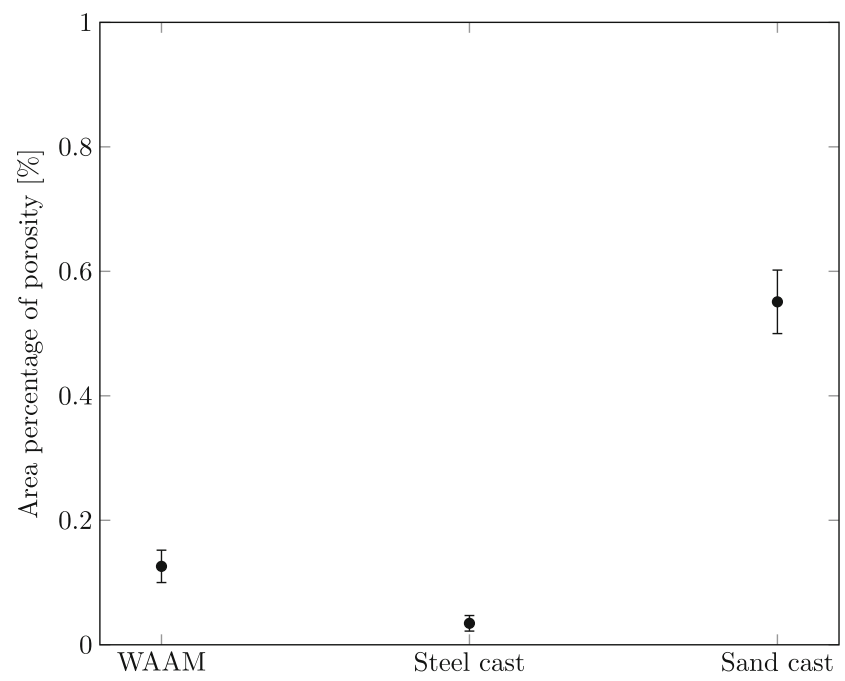

Fig. 5 Average area porosity of investigated materials over an area of $100 \mathrm{~mm}^{2}$. The steel mould casting was almost fully dense, followed by the WAAM block having slightly higher porosity. The sand mould casting has the highest amount of porosity

function of deposition parameters and wire manufacturer. The porosity deviated significantly from 0.3 to $3.0 \%$ by area. Fang et al. [32], on the other side, measured a relatively low area percentage $(0.36-0.85 \%)$ in AA5183 thin walls. Köhler et al. [33] compared the porosity content of AA5356 and AA4047 by visual inspection (no statistical data was given), and concluded AA5356 being denser. However, porosity is dependent on a wide range of parameters, such as deposition mode (GMAW/GTAW), wire quality, input deposition parameters and possibly component design (thin wall versus block).

Among all examined materials, the steel mould casting showed the lowest amount of porosity. A mixture of entrapped gas and shrinkage porosity was evenly distributed in the structure. The same characteristics were also found in the sand mould casting, but with relatively higher levels of porosity compared with the steel mould casting. The casting porosity levels are comparable with the observations of Tiedje et al. [34], who examined chill and sand castings of Sr-modified Al-12.5Si alloys. The area percentage of porosity in the sand mould castings in [34] and this study was almost identical, close to $0.6 \%$ by area.

All investigated materials possessed a dendritic microstructure as shown in Fig. 6 for WAAM and Fig. 7 for the castings. Individual weld beads deposited along the $X$ axis in Fig. 6a indicate a fluctuating dendrite structure in the transverse $Y Z$ plane, and is imaged at higher magnification in Fig. 6b. It is well known that primary $\alpha$ dendrites preferably grow along the largest heat flux upon solidification. This phenomenon is easily seen in the WAAM beads in Fig. $6 \mathrm{~b}$, with long $\alpha$ dendrites aligned towards the through thickness $Z$ direction. The driving force for nucleation of 


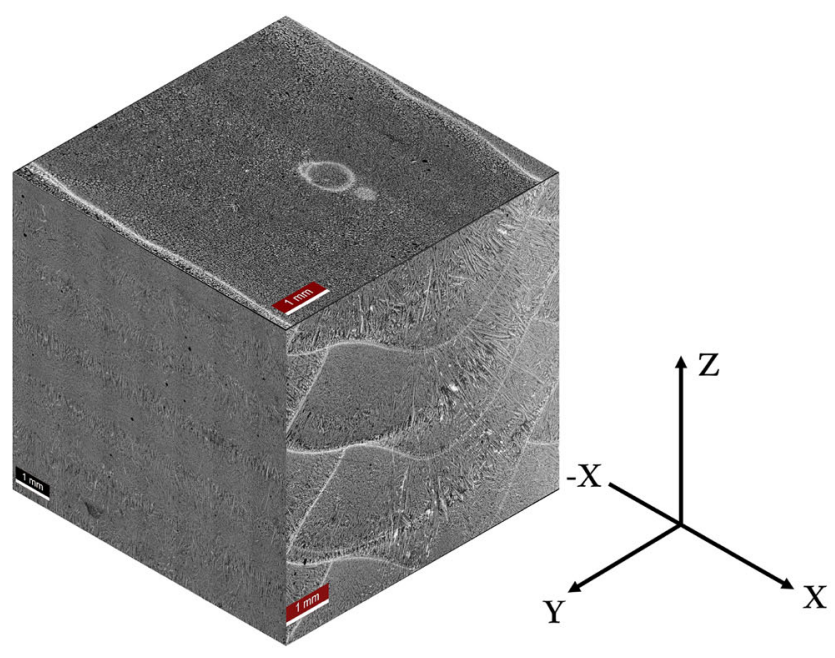

(a) WAAM block macrostructure in three perpendicular planes. Scale bars are $1 \mathrm{~mm}$

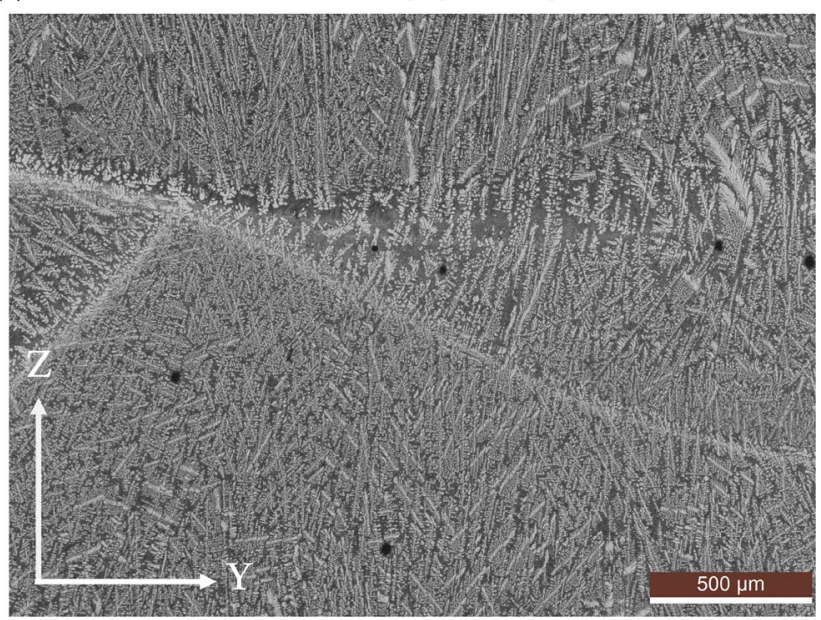

(b) Transverse $Y Z$ plane of the WAAM block showing coarser dendrites close to the fusion interface. Epitaxial growth on coarse dendrites is visible

Fig. 6 AA4047 WAAM microstructure, etched by Keller's reagent

aluminium is high during solidification of deposited beads in WAAM, manifested by numerous thin dendrites having underdeveloped secondary arms. The SEM image in Fig. 8a confirms the presence of a very fine eutectic structure in the WAAM material. The bright script-like $\mathrm{Al}_{15}(\mathrm{Fe}, \mathrm{Mn})_{3} \mathrm{Si}_{2}$ phase can also be seen, being the last constituent to solidify [35].

Deposition of a new layer on top of another leads to remelting of the existing weld bead during WAAM processing. This ensures adhesion between each layer, and can be seen as bright lines on the cube macrograph in Fig. 6a. At the weld bead interface, i.e. at bright lines, the material deposited in the former layer is partially remelted. The low temperature eutectic will then become liquid while $\alpha$-phase aluminium trunks stay in solid state where they ripen. Upon solidification of the newly deposited material, primary dendrites nucleate in an epitaxial manner on the coarsened dendrites from the fusion interface. Hence, solidification results in a columnar dendritic microstructure, which can imply anisotropic mechanical properties of the WAAM material.

The steel mould casting material had long primary dendrite trunks and underdeveloped secondary dendrite arms (see Fig. 7a). Primary $\alpha$-phase dendrites were generally longer and thicker in the steel mould casting compared with the WAAM microstructure. The sand mould casting microstructure consisted of well-developed dendrites, relatively coarse eutectic and primary silicon flakes. The eutectic lamellae distance fluctuated significantly (see Fig. 7b). The relatively coarser microstructures of the castings compared with the microstructure developed by WAAM are clearly shown by the high-magnification SEM images in Fig. 8.

The casting materials experienced a lower cooling rate than the WAAM counterpart, and resulted in two distinct effects in the solidified microstructure. Firstly, a lower cooling rate in casting enables primary $\alpha$-phase trunks to ripen and create a coarser microstructure. This is consistent with the well-established dendrites formed in the sand mould casting. Secondly, coarser Al-Si eutectic is formed with decreasing cooling rates, clearly showed in Figs. 6 and 7.

An EBSD orientation image of the AA4047 WAAM material is shown in Fig. 9. The dominating textures of primary $\alpha$ dendrites have been determined as $\{124\}<112>$ $\mathrm{R}$, together with $\{110\}<112>$ and $\{111\}<112>$ Brass components. These textures have also been observed in welded joints of commercial pure aluminium alloy AA1050 by Mironov et al. [36]. A less pronounced $\{102\}<221>$ T-texture was also observed in the WAAM material. The WAAM grain structure was dominated by epitaxial growth over the bead interface. Interlaying $\mathrm{Al}-\mathrm{Si}$ eutectic was relatively fine-grained and barely resolvable by the current EBSD setup. The average grain size of the investigated WAAM $Y Z$-plane area was $8.6 \mu \mathrm{m}$.

EBSD orientation maps of the castings are shown in Fig. 10. Casting materials were dominated by eutectic structures rather than primary dendrites, compared with the WAAM material. For instance, the examined area in the sand mould casting was purely eutectic. The average grain sizes for the steel mould casting and sand mould casting were $\sim 9.5 \mu \mathrm{m}$ and $\sim 20.2 \mu \mathrm{m}$, respectively.

However, the reported average grain size of each material can be misleading regarding fineness of structures due to different fractions of dendrites and eutectic. Generally, the $\mathrm{Al}-\mathrm{Si}$ eutectic has a finer grain size than $\alpha$ dendrites and can therefore influence the average grain size results. It is important to note that the WAAM microstructure exhibits both significantly finer primary dendrites and interlaying eutectic than the castings. The grain diameter distribution 
Fig. 7 Al-12Si casting microstructure, etched by Keller's reagent
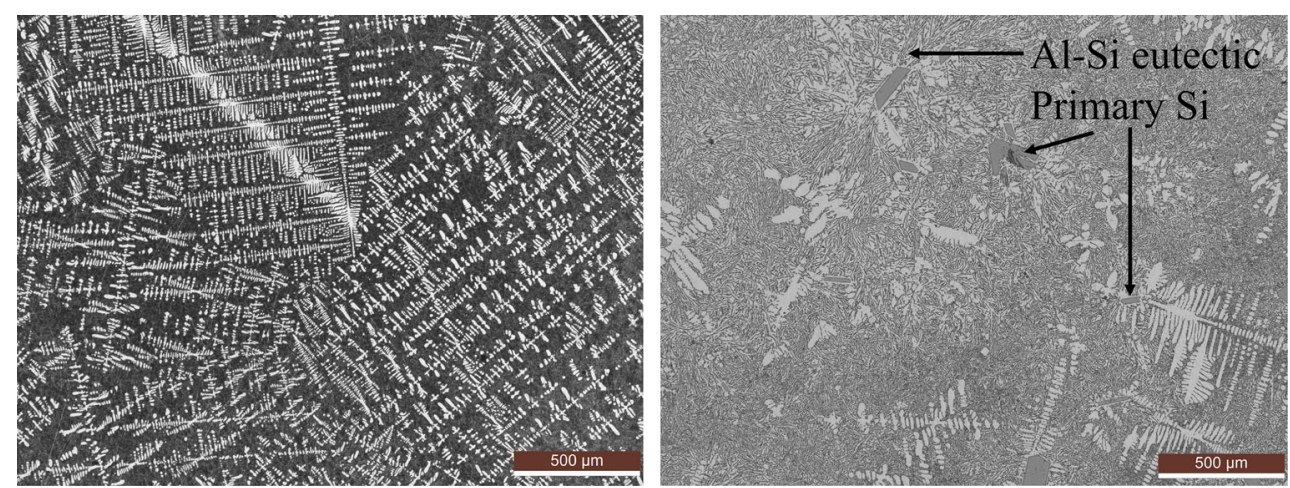

(b) Sand mould casting. Well developed den-

(a) Steel mould casting, showing long columnar dendrites drites, coarse Al-Si eutectic and primary $\mathrm{Si}$ are visible presented in Fig. 11 clearly illustrates this phenomenon. The number fraction of grains with a diameter less than $5 \mu \mathrm{m}$ drops significantly from WAAM to casting materials.

Secondary dendrite arm spacing $\left(\lambda_{2}\right)$ data of all investigated materials are summarised in Fig. 12. The WAAM material possessed a median $\lambda_{2}$ equal $6 \pm 1 \mu \mathrm{m}$. The result implies a slightly finer dendritic structure than the AA4047 WAAM component by Haselhuhn et al. [25], who obtained a median $\lambda_{2}$ of $8.2 \mu \mathrm{m}$. Median $\lambda_{2}$ for the steel mould casting was double the length of the WAAM material, i.e. $14 \pm 6 \mu \mathrm{m}$. The sand mould casting exhibited, as expected, the coarsest dendritic structure with median $\lambda_{2}$ of $29 \pm 6 \mu \mathrm{m}$.

The cooling rate in the examined materials can be estimated based on the secondary dendrite arm spacing $\lambda_{2}$. Earlier work has shown that aluminium alloys with
Fig. 8 SEM micrographs showing relative microstructural differences as a consequence of processing method
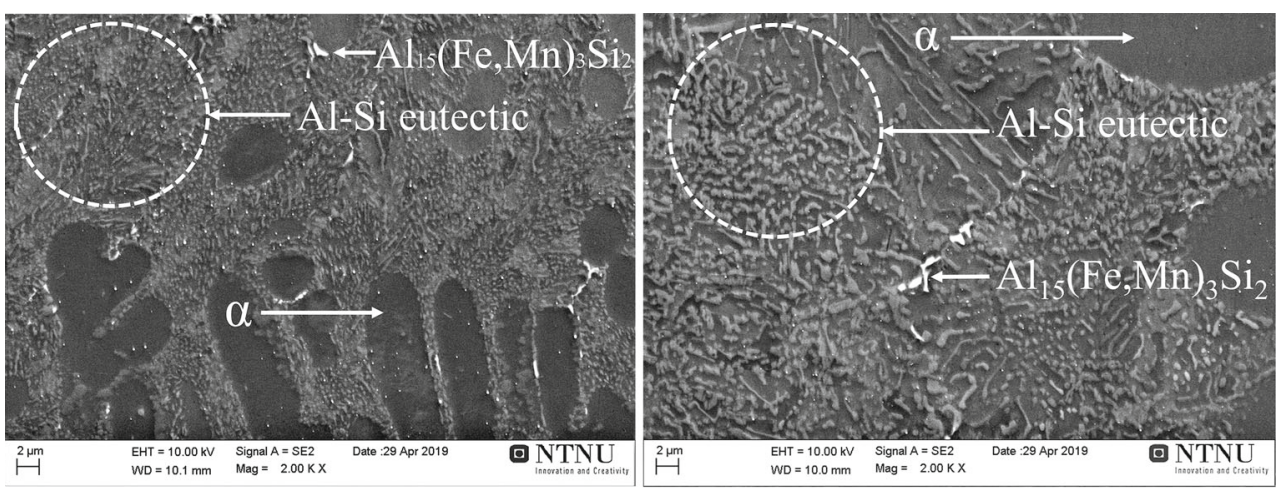

(a) AA4047 WAAM block

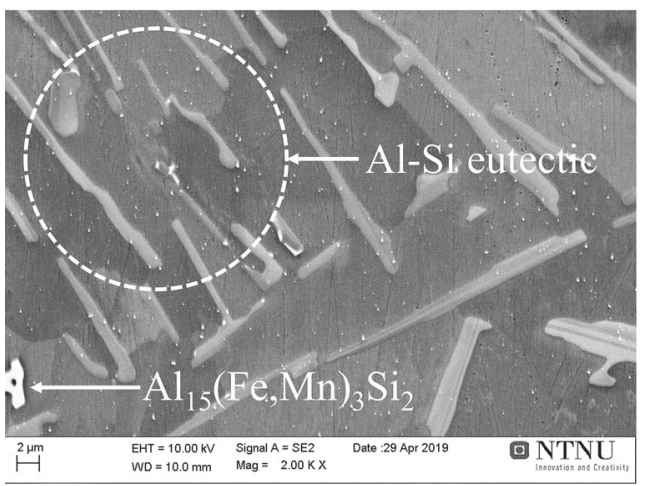

(b) Al-12Si steel mould casting

(c) Al-12Si sand mould casting 
Fig. 9 EBSD of AA4047

WAAM block in the $Y Z$ plane.

Average grain size $8.6 \mu \mathrm{m}$

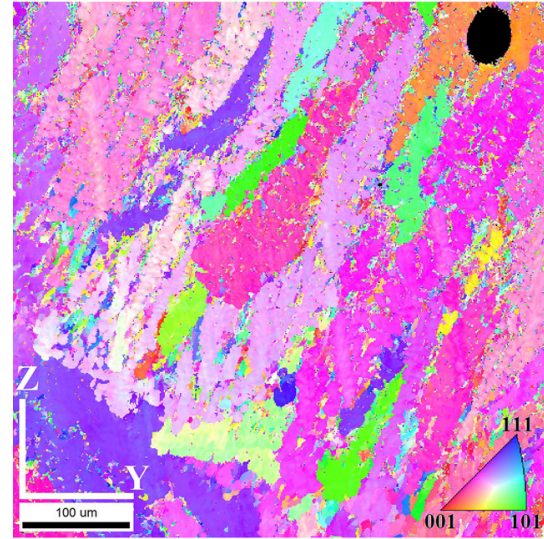

(a) Inverse pole figure



(b) Image Quality map high silicon content tends to follow the relation given in Eq. 2 [26]. Here, $B$ and $n$ are material constants and $\lambda_{2}$ the secondary dendrite arm spacing. For (hypo)eutectic AlSi alloys, $B$ and $n$ have values of $50(\mathrm{~K} / \mathrm{s})^{n}$ and 0.33 , respectively $[37,38]$.

Cooling rate $=\left(\frac{B}{\lambda_{2}}\right)^{1 / n}$

Based on a calculation using Eq. 2, the WAAM block material exhibited a median cooling rate close to $550 \mathrm{~K} / \mathrm{s}$, Fig. 13. Median cooling rates of the steel mould and sand mould castings were significantly lower, i.e. $50 \mathrm{~K} / \mathrm{s}$ and $5 \mathrm{~K} / \mathrm{s}$, respectively. The deviation in cooling rate of both the WAAM material and steel mould-casted materials is high due to the underdeveloped secondary dendrite arms, which complicates the quantification of $\lambda_{2}$. Equation 2 is also prone to large variations in cooling rate when $\lambda_{2}$ approaches zero. Consequently, the WAAM structure has a large variation in estimated cooling rate despite a narrow size distribution of $\lambda_{2}$ (Fig. 12).

\subsection{Mechanical properties}

Isostatic tensile results for three perpendicular directions in the AA4047 WAAM material and one direction of the Al-12Si steel mould casting are shown in Fig. 14. The steel mould casting possessed statistically significant lower mechanical properties compared with the WAAM counterpart $(p<0.05)$. The ultimate tensile strength $\sigma_{T S}$ for WAAM ranged from $226 \pm 6$ to $233 \pm 5 \mathrm{MPa}$, while being $219 \pm 4 \mathrm{MPa}$ for the steel mould casting. The steel mould product also showed lower ductility with $8 \%$ elongation before fracture, compared with $11-14 \%$ for the WAAM material. For comparison, Haselhuhn et al. [25] manufactured AA4047 thin walls by WAAM and obtained a $\sigma_{T S}$ of $180 \mathrm{MPa}$, which is significantly lower than the values reported in this study.

The tensile results reveal a statistical significant anisotropy in terms of strength and elongation between the $X$ and $Y$ directions in the WAAM material $(p<0.05)$. Similarly, a significant difference in elongation was found between the $X$ and $Z$ directions. It should be noted that
Fig. 10 EBSD orientation images of castings

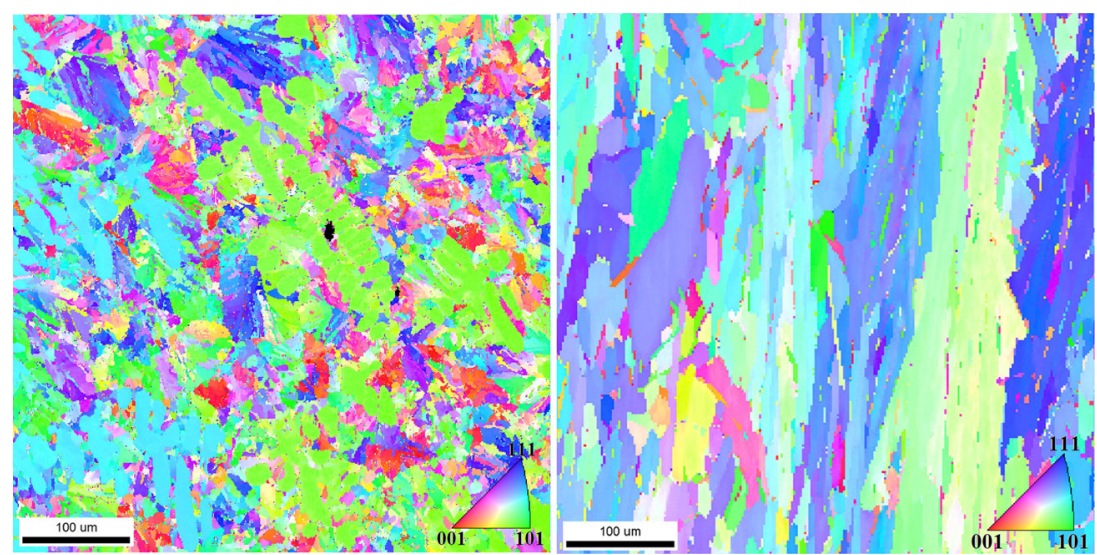

(a) Steel mould casting grain structure. Aver- (b) Sand mould casting grain structure. Average grain size $9.5 \mu \mathrm{m}$ age grain size $20.2 \mu \mathrm{m}$ 




Fig. 11 Grain diameter distribution of the investigated materials. The WAAM material exhibits a significantly higher fraction of grains with diameter $<5 \mu \mathrm{m}$ compared with the casted counterparts. The plots are based on EBSD data from Figs. 9 and 10

the WAAM direction with lowest strength possessed highest ductility, i.e. the deposition direction $X$. The ductility in each direction can be directly related to the orientation and volume fraction of fusion interfaces. The interface between each bead has a relatively coarser dendritic and eutectic microstructure as seen in Fig. 6b, and may be vulnerable for onset of microcrack nucleation and growth. An increasing fraction of fusion interfaces in the gauge area of a tensile specimen increases the probability for unstable crack growth, which in turn yields lower ductility. As seen in Fig. 15, the $Y$ and $Z$ directions cross more interfaces than the deposition direction $X$. Thus, the $X$ direction is most ductile.

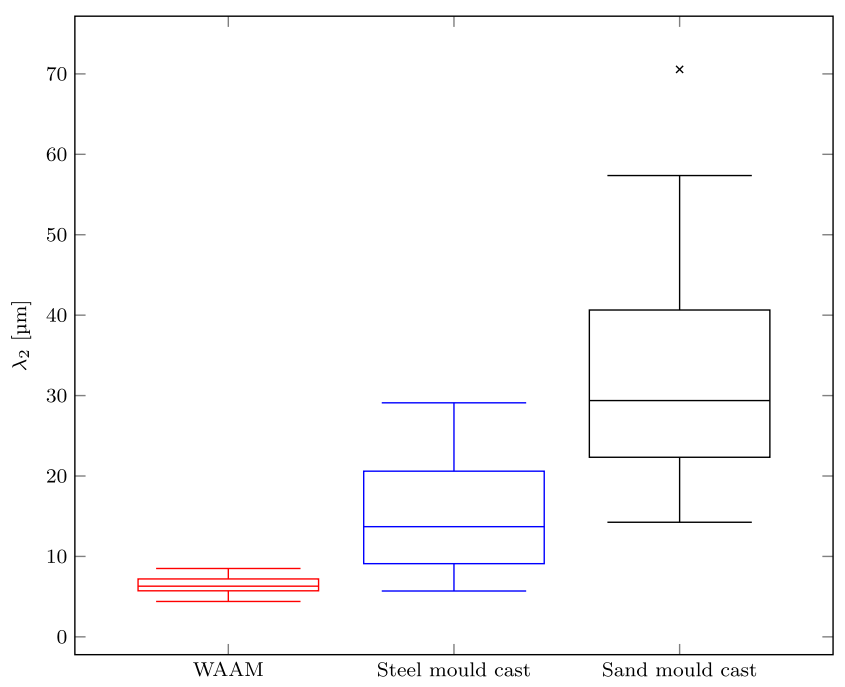

Fig. 12 Secondary dendrite arm spacing $\left(\lambda_{2}\right)$ for the investigated materials. The median, upper and lower quartiles and whiskers are shown. The sand mould data set had one outlier

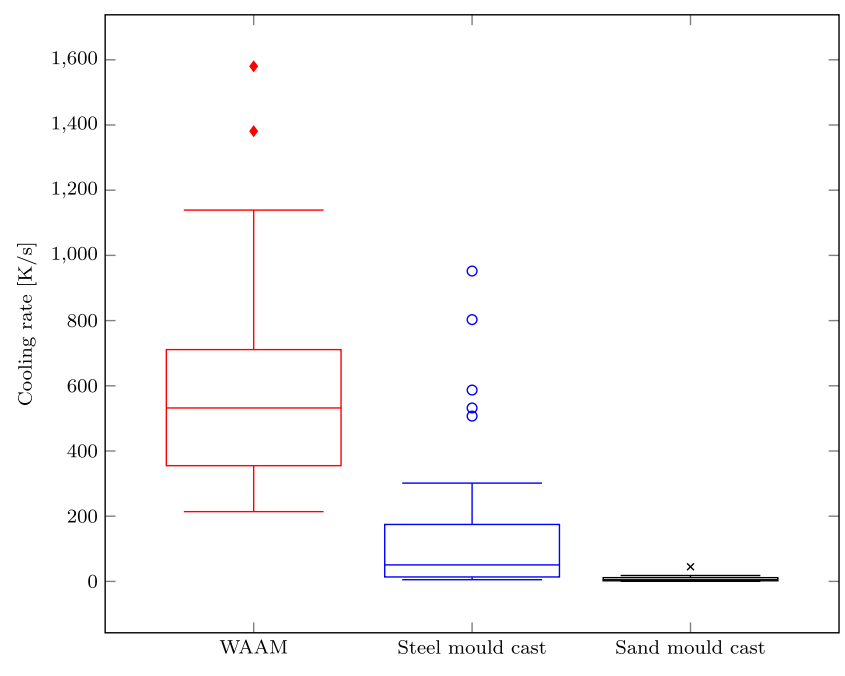

Fig. 13 Cooling rate of all investigated materials, based on the secondary dendrite arm spacing $\lambda_{2}$. All data sets had outliers over the upper whisker

It is well-known that the critical resolved shear stress to initiate dislocation slip during plastic deformation is at maximum $45^{\circ}$ relative to the tensile direction for isotropic materials. Weak interfaces oriented with higher resolved shear stress are therefore expected to yield lower ductility. This is in fact the case for the $Y$ orientation in Fig. 15, where the fusion beads cross $\sim 45^{\circ}$ over the gauge area. Although the WAAM material is slightly anisotropic due to small differences in E-moduli for the three perpendicular directions, it can be considered isotropic in the elastic stage. The resolved shear stress is thus highest for the $Y$ tensile direction, which corresponds well with the results from tensile testing (Fig. 14).

Variation in Vickers microhardness as a function of position in the WAAM material is shown in Fig. 16. Blue

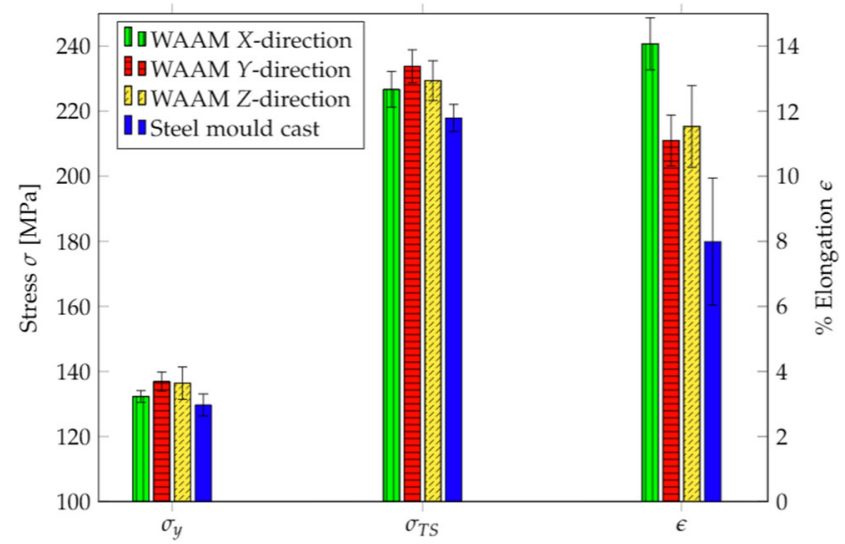

Fig. 14 Yield stress $\left(\sigma_{y}\right)$, ultimate tensile stress $\left(\sigma_{T S}\right)$ and elongation at fracture $(\epsilon)$ of investigated materials. The WAAM material outperforms the steel mould casting, both in terms of strength and tensile ductility 
Fig. 15 Representation of circular tensile gauge area $(\phi 3 \mathrm{~mm} \times 30 \mathrm{~mm})$ for the three perpendicular $X, Y$ and $Z$ directions. The tensile $X$ direction having highest ductility cross less fusion bead interfaces compared to the $Y$ and $Z$ directions

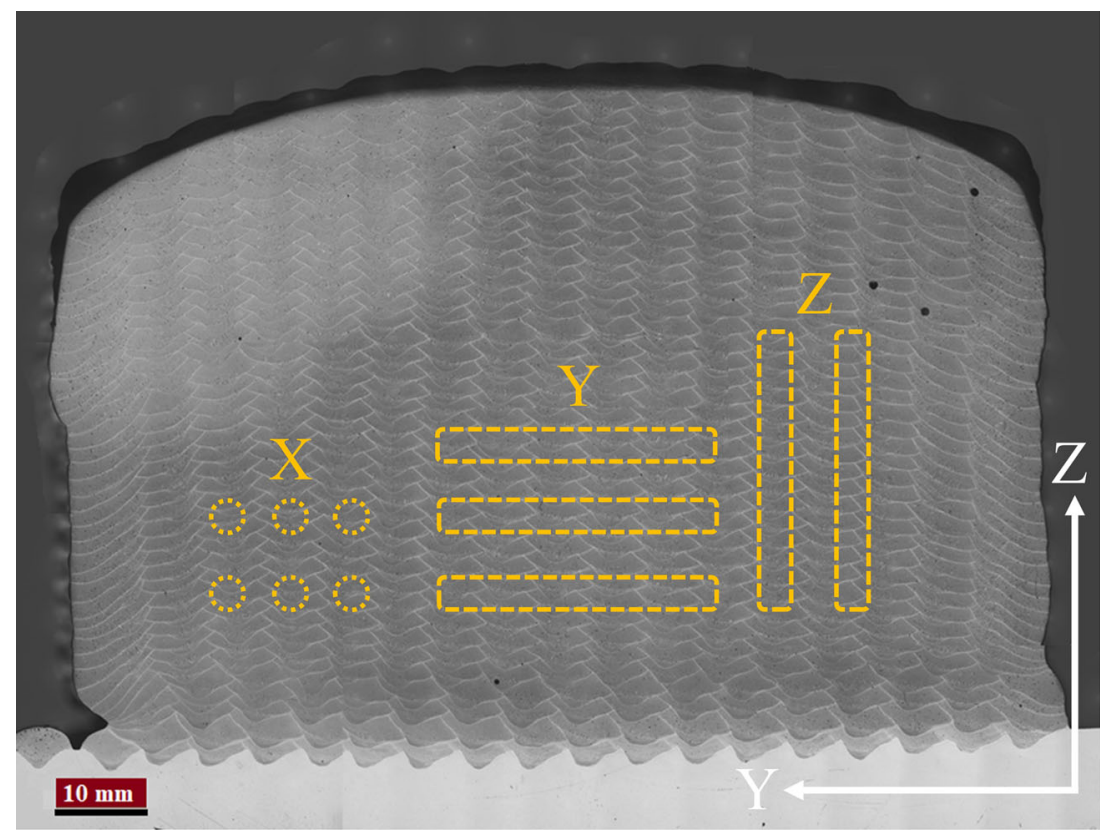

points indicate softer spots in the material. A clear relation between the coarser microstructure at the bead fusion interfaces (blue lines in Fig. 16) and low microhardness can be seen. The highest hardness values are located in centre locations of beads and close to $80 \mathrm{HV}_{0.1}$, being similar to the results reported by Hirtler et al. [39] for a similar Al-12Si alloy manufactured by WAAM.

Similar microhardness maps were developed for the castings (see Fig. 17). The blunt end (i.e. bottom of the casting) was chosen as the area of investigation. Several trends can be drawn from the results. Both casting materials seem to be softer towards the edges. Naturally, the cooling rate is highest towards the mould walls. A high cooling rate increases the driving force for nucleation of primary $\alpha$ dendrites and creates a higher fraction of $\alpha$-phase than of Al-Si eutectic. As $\alpha$-phase is softer than the fine eutectic, edge softening originates from a depletion of interdendritic eutectic at the edges.

Some relative differences in the hardness distribution of the respective castings were also observed. Firstly, the steel mould casting exhibited higher hardness than the sand mould parallel. This is due to a finer microstructure of the steel mould casting. Secondly, the sand mould casting showed a highly fluctuating hardness. This heterogeneity
Fig. 16 Vickers microhardness map of AA4047 WAAM block material in the $Y Z$ plane. Blue lines indicate fusion interfaces between individual beads. The colour scale bar to the right indicates hardness $\mathrm{HV}_{0.1}$




Fig. 17 Vickers microhardness maps of casting materials. The colour scale bars indicate hardness $\mathrm{HV}_{0.1}$

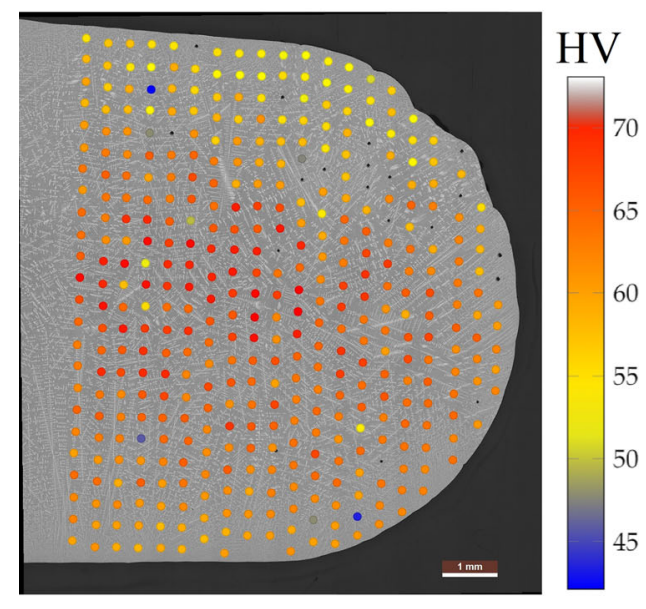

(a) Al-12Si steel mould casting

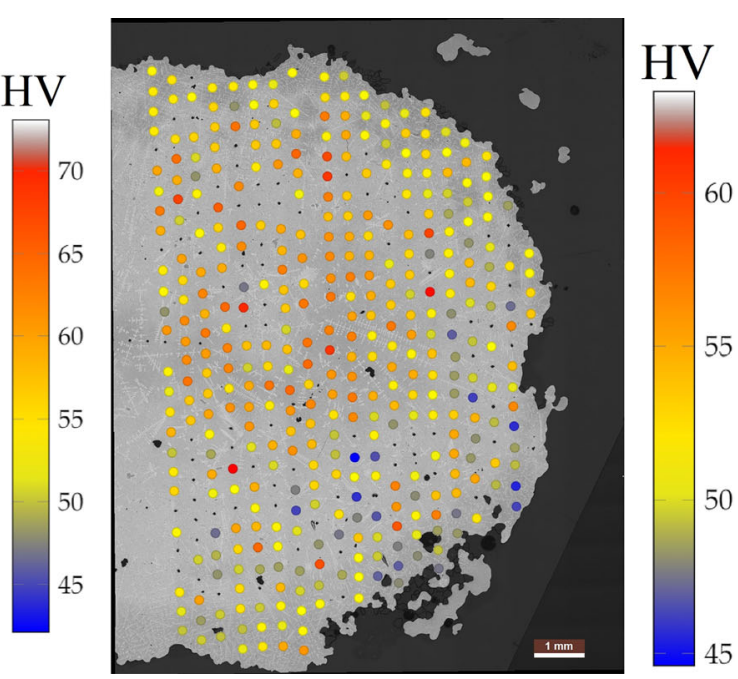

(b) Al-12Si sand mould casting can be associated with the highly fluctuating eutectic lamella distance of the Al-Si phase. In areas with fine lamellae, the hardness is higher (red/orange colour) while softer areas (grey/blue colour) occur in positions with coarser eutectic microstructure.

\subsection{Production efficiency}

The WAAM block was built in $18 \mathrm{~h}$ and had a total mass of $3790 \mathrm{~g}$, resulting in an average deposition rate of $210 \mathrm{~g} / \mathrm{h}$. However, a large portion of the manufacturing time was related to interpass waiting to chill the structure. If WAAM is utilised for larger structures where the former layer has cooled down sufficiently before the next layer is deposited, continuous manufacturing can be attainable. For the presented WAAM block manufacture, $11 \mathrm{~h}$ was used for interpass cooling. For another design where waiting time can be eliminated, the deposition rate with the given WAAM parameters increase to approximately $550 \mathrm{~g} / \mathrm{h}$. The deposition rate is one order of magnitude higher for WAAM compared with powder bed AM methods [40], and this highlights the potential of WAAM for production of large-scale components.

Components made by WAAM consist of many weld beads with a relatively homogeneous microstructure. Mechanical properties are thus independent of component design geometry. This is in opposition to casted materials, which exhibits increasing fluctuation of through thickness properties with increasing component dimensions. A thick casting will generally consist of fine equiaxed grains in the vicinity of the mould wall, columnar dendrites towards the centre and coarse equiaxed dendrites in the centre. Such microstructure heterogeneity may lower the mechanical properties.

\section{Conclusions}

The microstructure and mechanical properties of aluminium-silicon alloys with near eutectic composition made by wire and arc additive manufacturing have been benchmarked against two different casting methods. The WAAM material exhibited superior mechanical properties over castings due to a higher cooling rate during solidification and consequently a finer microstructure. All materials showed relative low levels of porosity, i.e. less than $1 \%$ (area percentage). The WAAM material is made out of individual beads which exhibit low through thickness variations of the microstructure in thicker sections. This feature is in contrast to casting with lower cooling rates and large thickness variations of the microstructure. WAAM is a fairly slow manufacturing method compared with casting; a deposition rate up to $550 \mathrm{~g} / \mathrm{h}$ can be obtained with the current setup. Thus, WAAM might be utilised when high mechanical integrity is required or when casting mould designs become very complex.

Acknowledgements The authors would also like to acknowledge Mr. Morten H. Danielsen, Ms. Linn D. Evjemo and Mr. Arne Nordmark for their experimental support related to WAAM and casting.

Funding information Open Access funding provided by NTNU Norwegian University of Science and Technology (incl St. Olavs Hospital - Trondheim University Hospital). The authors received funding from the Research Council of Norway through Contract No. 272402 .

\section{Compliance with ethical standards}

Conflict of interest The authors declare that they have no conflict of interest. 
Open Access This article is licensed under a Creative Commons Attribution 4.0 International License, which permits use, sharing, adaptation, distribution and reproduction in any medium or format, as long as you give appropriate credit to the original author(s) and the source, provide a link to the Creative Commons licence, and indicate if changes were made. The images or other third party material in this article are included in the article's Creative Commons licence, unless indicated otherwise in a credit line to the material. If material is not included in the article's Creative Commons licence and your intended use is not permitted by statutory regulation or exceeds the permitted use, you will need to obtain permission directly from the copyright holder. To view a copy of this licence, visit http:// creativecommonshorg/licenses/by/4.0/.

\section{References}

1. Sames WJ, List FA, Pannala S, Dehoff RR, Babu SS (2016) The metallurgy and processing science of metal additive manufacturing. Int Mat Rev 61(5):315. https://doi.org/10.1080/09506608. 2015.1116649

2. Bikas H, Stavropoulos P, Chryssolouris G (2016) Additive manufacturing methods and modelling approaches: a critical review. Int J Adv Manuf Technol 83(1-4):389. https://doi.org/10.1007/s001 70-015-7576-2

3. Saunders S (2017) After successful testing and verification, 3D printed WAAMpeller is introduced to the public. 3DPrint.com. Available at: https://3dprint.com/195791/3d-printed-waampellerverified/. Last visited 07.06.2020

4. Thompson MK, Moroni G, Vaneker T, Fadel G, Campbell RI, Gibson I, Bernard A, Schulz J, Graf P, Ahuja B, Martina F (2016) Design for additive manufacturing: trends, opportunities, considerations, and constraints. CIRP Ann 65(2):737. https://doi.org/10.1016/j.cirp.2016.05.004

5. Dowling A (2020) Printing a high performance fuel nozzle. asme.com (2013). Available at: https://www. asme.org/engineering-topics/media/aerospace-defense/ video-printing-high-performance-fuel-nozzle. Last visited 07.06.2020

6. Baker R. (1925) Method of making decorative articles. US Patent No. $1,533,300$

7. Williams SW, Martina F, Addison AC, Ding J, Pardal G, Colegrove P (2016) Wire, + arc additive manufacturing. Mater Sci Technol 32(7):641. https://doi.org/10.1179/1743284715Y.000000 0073

8. Lewandowski JJ, Seifi M (2016) Metal additive manufacturing: a review of mechanical properties. Annu Rev Mater Res 46:151. https://doi.org/10.1146/annurev-matsci-070115-032024

9. Xiong J, Lei Y, Chen H, Zhang G (2017) Fabrication of inclined thin-walled parts in multi-layer single-pass gMAW-based additive manufacturing with flat position deposition. J Mater Process Technol 240:397. https://doi.org/10.1016/j.jmatprotec.2016.10.019

10. Spierings AB, Starr TL, Wegener K (2013) Fatigue performance of additive manufactured metallic parts. Rapid Prototyp J 19(2):88. https://doi.org/10.1108/13552541311302932

11. Strößner J, Terock M, Glatzel U (2015) Mechanical and microstructural investigation of nickel-based superalloy IN718 manufactured by selective laser melting (SLM). Adv Eng Mater 17(8):1099. https://doi.org/10.1002/adem.201500158

12. Guo J, Zhou Y, Liu C, Wu Q, Chen X, Lu J (2016) Wire arc additive manufacturing of aZ31 magnesium alloy: grain refinement by adjusting pulse frequency. Mater 9(10):823. https://doi.org/10.3390/ma910082
13. Loeber L, Biamino S, Ackelid U, Sabbadini S, Epicoco P, Fino P, Eckert J (2011) In proceedings of the solid freeform fabrication symposium, Austin, TX, USA. pp 547-566

14. Brif Y, Thomas M, Todd I (2015) The use of highentropy alloys in additive manufacturing. Scr Mater 99:93. https://doi.org/10.1016/j.scriptamat.2014.11.037

15. Fujieda T, Shiratori H, Kuwabara K, Kato T, Yamanaka K, Koizumi Y, Chiba A (2015) First demonstration of promising selective electron beam melting method for utilizing highentropy alloys as engineering materials. Mater Lett 159:12. https://doi.org/10.1016/j.matlet.2015.06.046

16. Mathers G (2002) The welding of aluminium and its alloys (Woodhead publishing). ISBN 978-1-85573-567-5

17. Aylward G, Findlay T (2008) SI chemical data, 6th Ed (Wiley Ltd). ISBN 9780470816387

18. Gu JL, Ding JL, Cong BQ, Bai J, Gu HM, Williams SW, Zhai YC (2015) Advanced materials research, vol 1081 (Trans Tech Publ), pp 210-214. https://doig.org/10.4028/www.scientific.net/AMR. 1081.210

19. Sonsino CM, Ziese J (1993) Fatigue strength and applications of cast aluminium alloys with different degrees of porosity. Int J Fatigue 15(2):75. https://doi.org/10.1016/0142-1123(93)900 01-7

20. Gu J, Ding J, Williams SW, Gu H, Bai J, Zhai Y, Ma P (2016) The strengthening effect of inter-layer cold working and postdeposition heat treatment on the additively manufactured Al-6.3 $\mathrm{Cu}$ alloy. Mater Sci Eng A 651:18. https://doi.org/10.1016/j. msea.2015.10.101

21. Bai J, Ding HL, Gu JL, Wang XS, Qiu H (2017) In IOP conference series: materials science and engineering, vol 167 (IOP Publishing), p 012045. https://doi.org/10.1088/1757-899X/167/1/012 045

22. Wang D, Lu J, Tang S, Yu L, Fan H, Ji L, Liu C (2018) Reducing porosity and refining grains for arc additive manufacturing aluminum alloy by adjusting arc pulse frequency and current. Mater 11(8):1344. https://doi.org/10.3390/ma11081344

23. Horgar A, Fostervoll H, Nyhus B, Ren X, Eriksson M, Akselsen OM (2018) Additive manufacturing using WAAM with AA5183 wire. J Mater Process Technol 259:68. https://doi.org/10.1016/j. jmatprotec.2018.04.014

24. Fixter J, Gu J, Ding J, Williams SW, Prangnell PB (2017) In materials science forum. vol 877 (Trans Tech Publ) pp 611-616. https://doi.org/10.4028/www.scientific.net/MSF.877.611

25. Haselhuhn AS, Buhr MW, Wijnen B, Sanders PG, Pearce JM (2016) Structure-property relationships of common aluminum weld alloys utilized as feedstock for GMAW-based 3-D metal printing. Mater Sci Eng A 673:511. https://doi.org/10.1016/j. msea.2016.07.099

26. Heard DW, Brophy S, Brochu M (2012) Solid freeform fabrication of al-Si components via the CSC-MIG process. Can Metall Q 51(3):302. https://doi.org/10.1179/1879139512Y.0000000 023

27. Shamsuzzoha M, Hogan LM (1986) The crystal morphology of fibrous silicon in strontium-modified Al-Si eutectic. Philos Mag A 54(4):459. https://doi.org/10.1080/01418618608243 605

28. Horgar A (2018) Comparative study of mechanical properties and microstructure of components made by casting and wire + arc additive manufacturing of eutectic Al-12Si alloy. Master's thesis, NTNU. http://hdl.handle.net/11250/2622352

29. Vandersluis E, Ravindran C (2017) Comparison of measurement methods for secondary dendrite arm spacing. Metallogr Microstruct Anal 6(1):89. https://doi.org/10.1007/s13632016-0331-8 
30. Ortega AG, Corona Galvan L, Salem M, Moussaoui K, Segonds S, Rouquette S, Deschaux-Beaume F (2019) Characterisation of 4043 aluminium alloy deposits obtained by wire and arc additive manufacturing using a cold metal transfer process. Sci Technol Weld Join 24(6):538. https://doi.org/10.1080/13621718.2018. 1564986

31. Ryan EM, Sabin TJ, Watts JF, Whiting MJ (2018) The influence of build parameters and wire batch on porosity of wire and arc additive manufactured aluminium alloy 2319. J Mater Process Technol 262:577. https://doi.org/10.1016/j.jmatprotec.2018.07.030

32. Fang X, Zhang L, Chen G, Dang X, Huang K, Wang L, Lu B (2018) Correlations between microstructure characteristics and mechanical properties in 5183 aluminium alloy fabricated by wire-arc additive manufacturing with different arc modes. Mater 11(11):2075. https://doi.org/10.3390/ma11112075

33. Köhler M., Fiebig S, Hensel J, Dilger K (2019) Wire and arc additive manufacturing of aluminum components. Met 9(5):608. https://doi.org/10.3390/met9050608

34. Tiedje NS, Taylor JA, Easton MA (2012) Feeding and distribution of porosity in cast Al-Si alloys as function of alloy composition and modification. Metall Mater Trans A 43(12):4846. https://doi.org/10.1007/s11661-012-1308-0
35. Caceres CH, Taylor JA (2006) Enhanced ductility in Al-Si-Cu$\mathrm{Mg}$ foundry alloys with high Si content. Metall Mater Trans B 37(6):897. https://doi.org/10.1007/BF02735011

36. Mironov S, Masaki K, Sato YS, Kokawa H (2013) Texture produced by abnormal grain growth in friction stir-welded aluminum alloy 1050. Metall Mater Trans A 44(3):1153. https://doi.org/10.1007/s11661-012-1596-4

37. Su S, Moran LA, Lavernia EJ (1994) Solidification behavior of an al-6Si alloy during spray atomization and deposition. Int J Rap S 8(3): 161

38. Jarfors AEW (1998) Solidification behaviour of Al-7\% Si-0.3\% $\mathrm{Mg}$ during rotary spray forming, vol 33. https://doiörg/10.1023/ A:1004632326038

39. Hirtler M, Jedynak A, Sydow B, Sviridov A, Bambach M In MATEC web of conferences, vol 190 (EDP Sciences, 2018), p 02005. https://doi.org/10.1051/matecconf/201819002005

40. Zenou M, Grainger L (2018) Additive manufacturing of metallic materials, Addit. Manuf. pp 53-103. https://doi.org/10.1016/B9 78-0-12-812155-9.00003-7

Publisher's note Springer Nature remains neutral with regard to jurisdictional claims in published maps and institutional affiliations. 